\title{
ULTIMATE-SHF trial (UdenafiL Therapy to Improve symptoMAtology, exercise Tolerance and hEmodynamics in patients with chronic systolic heart failure): study protocol for a randomized, placebo-controlled, double-blind trial
}

Kyung-Hee Kim ${ }^{1,2}$, Hyung-Kwan Kim ${ }^{1,2^{*}}$, In-Chang Hwang ${ }^{1,2}$, Seung-Pyo Lee ${ }^{1,2}$, Hyun-Jai Cho ${ }^{1,2}$, Hyun-Jae Kang ${ }^{1,2}$, Yong-Jin $\mathrm{Kim}^{1,2}$ and Dae-Won Sohn ${ }^{1,2}$

\begin{abstract}
Background: Over the last few years, the use of phosphodiesterase type 5 (PDE5) inhibitors has been expanded to management of various cardiovascular disorders beyond pulmonary arterial hypertension. This study is designed to investigate the ability of udenafil, a newly developed long-acting PDE5 inhibitor, to improve functional capacity and hemodynamic status in a cohort of chronic systolic heart failure (SHF) patients.

Methods/design: Stable, chronic SHF patients will be randomly assigned to placebo (26 patients) or udenafil at a dose of $50 \mathrm{mg}$ twice per day (26 patients) for the first 4 weeks followed by $100 \mathrm{mg}$ twice daily for the next 8 weeks. Eligibility criteria will be age $\geq 18$ years, clinical diagnosis of chronic SHF with current New York Heart Association class II to IV symptoms, left ventricular ejection fraction $\leq 40 \%$, and experience of at least one of following during the 12 months prior to study entry: hospitalization for decompensated heart failure, acute treatment with intravenous loop diuretics or hemofiltration, or pulmonary artery systolic pressure $\geq 40 \mathrm{mmHg}$ on transthoracic echocardiography. Pharmacological therapy for SHF will be optimized in all patients at least 30 days before study entry. The primary outcome will be the change of maximal oxygen uptake, assessed by cardiopulmonary exercise testing. Secondary outcomes will include changes in ventilatory efficiency (minute ventilation/carbon dioxide production slope), left ventricular systolic and diastolic parameters, pulmonary artery systolic pressure, plasma concentration of brain natriuretic peptide, occurrence of mortality or hospitalization for heart failure, and the occurrence of any adverse event.
\end{abstract}

Clinical trial registration: Unique identifier: NCT01646515

Keywords: Phosphodiesterase type 5 inhibitor, Udenafil, Chronic heart failure, Exercise capacity

\footnotetext{
* Correspondence: cardiman73@gmail.com

'Department of Internal Medicine, Seoul National University College of Medicine, Seoul 110-744, Korea

${ }^{2}$ Cardiovascular Center, Seoul National University Hospital, Seoul 110-744, Korea
} 


\section{Background}

Heart failure is a leading cause of death that continues to cause a significant socioeconomic burden worldwide [1]. The prevalence of chronic heart failure (HF) in relation to left ventricular (LV) systolic dysfunction is estimated to be as high as 2 to $11 \%$ [2]. Despite the aggressive use of medications, such as angiotensin-converting enzyme inhibitors, $\beta$-blockers and spironolactone, proven to improve the survival of chronic HF patients with a reduced LV ejection fraction, mortality and morbidity remain high, and one of the potential reasons for this might be the development of pulmonary hypertension. According to a number of earlier works, up to $60 \%$ of patients with severe LV systolic dysfunction develop pulmonary hypertension $[3,4]$. Hence, it is conceivable that the development of pulmonary venous or mixed pulmonary venous/arterial hypertension, which results in HF symptoms such as dyspnea and limitation of exercise capacity, and consequently adversely affects quality of life and prognosis, is an important milestone in the progression of uncomplicated LV systolic dysfunction to clinically manifested HF. In this respect, development of a new therapeutic option that deals with the issue of pulmonary hypertension in association with LV systolic failure is both attractive and clinically relevant.

Phosphodiesterase type 5 (PDE5) is a key enzyme in the catabolism of cyclic guanine monophosphate (cGMP) and is predominantly abundant in the vascular smooth muscle cells of the pulmonary vasculature [5]. Given the important role of cGMP in the regulation of nitric oxide and that defective nitric oxide release is a major factor of vasoconstriction in chronic HF [6], the addition of PDE5 inhibitors to established medications for chronic HF could be a theoretically appealing treatment strategy. PDE5 inhibitors were initially introduced as a treatment option for erectile dysfunction, and even in the late 20th century this type of drug was believed to have little to contribute in the cardiology field. However, since PDE5 inhibitors were found to have beneficial effects on pulmonary arterial hypertension in man [7], and the confirmation of this finding in clinical trials [8,9], PDE5 inhibition is now considered a viable therapeutic option for the treatment of pulmonary arterial hypertension. In addition to their favorable therapeutic impacts on pulmonary arterial hypertension, PDE5 inhibitors have recently been shown to be effective therapeutics in patients with chronic systolic heart failure (SHF) $[8,10]$.

Udenafil (Zydena ${ }^{\circledR}$; Dong-A Pharmaceutical Company, Seoul, South Korea) is a newly developed long-acting PDE5 inhibitor [11,12], with efficacy and safety profiles comparable with those of other PDE5 inhibitors [13]. Udenafil is similar to sildenafil in molecular structures (Figure 1), and is comparable with sildenafil in terms of PDE5 selectivity and its broad range of safety margin

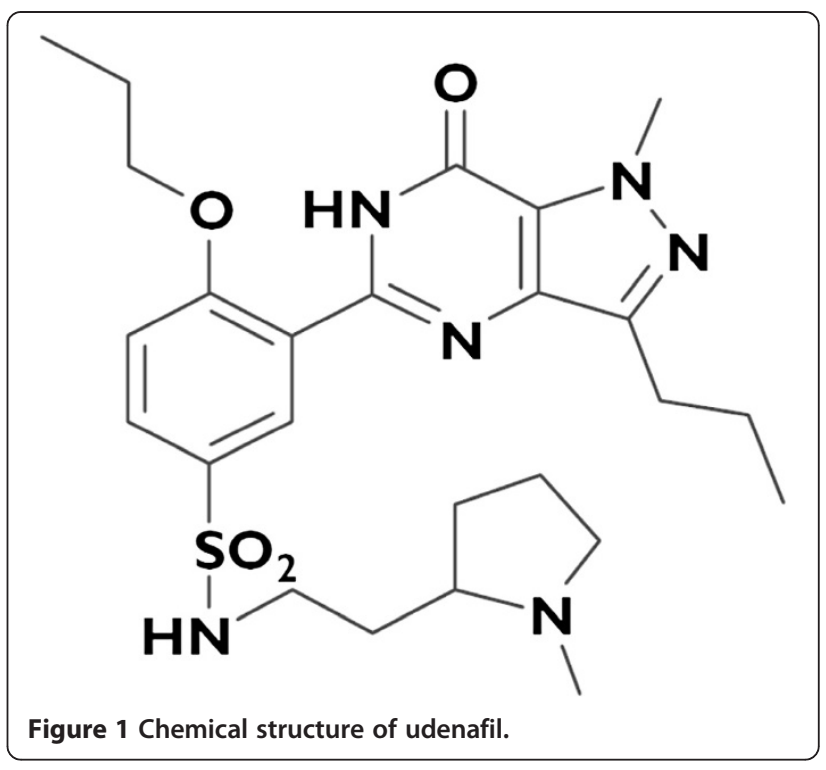

[14]. Furthermore, laboratory data showed that udenafil inhibits ventricular hypertrophy and fibrosis in a rat HF model [15]. In the preclinical study, udenafil increased serum cGMP levels, decreased intracellular $\mathrm{Ca}^{2+}$ concentrations, and produced vasodilatation. In this proposed double-blind, randomized, placebo-controlled trial we hypothesize that udenafil will ameliorate symptoms, and improve exercise capacity and hemodynamic status in patients with chronic SHF (ULTIMATE-SHF trial; NCT01646515).

\section{Methods/design \\ Study population}

The ULTIMATE-SHF trial is designed as a prospective, single-center, randomized, double-blind, placebo-controlled study targeting patients with chronic SHF, in whom optimal medical therapy has been established. Patients with stable chronic SHF that meet the prespecified eligibility criteria and provide written informed consent will be enrolled (Table 1). Detailed information on benefits and risks will be provided to study candidates. Pharmacological therapy for heart failure will be optimized in all patients at least 30 days before study entry.

\section{Study design and medications}

Patient screening for trial eligibility will be based on reviews of medical records and echocardiographic results before baseline visits. After confirming study eligibility, baseline examinations (see the next section) will be conducted. Subsequently, patients will be randomized in a double-blind fashion to receive either udenafil or placebo (1:1) on top of any background therapeutic regimen in compliance with current recommendations [16], utilizing the randomization scheme depicted in Figure 2. 
Table 1 Eligibility criteria

\begin{tabular}{|c|c|}
\hline Inclusion criteria & Exclusion criteria \\
\hline 1. Able to provide written informed consent & $\begin{array}{l}\text { 1. FEV } 1<80 \% \text { of predicted value or FEV1/FVC }<70 \% \text { on spirometry at } \\
\text { screening }\end{array}$ \\
\hline 2. Men and women $\geq 18$ years old & 2. Other valve diseases greater than mild stenosis and/or regurgitation \\
\hline $\begin{array}{l}\text { 3. Established clinical diagnosis of chronic systolic heart failure with } \\
\text { NYHA class II to IV symptoms currently }\end{array}$ & $\begin{array}{l}\text { 3. Neuromuscular, orthopedic, or other noncardiac conditions that } \\
\text { prevent completion of a maximal exercise testing }\end{array}$ \\
\hline \multirow{2}{*}{$\begin{array}{l}\text { 4. Left ventricular ejection fraction } \leq 40 \% \text {, as determined by } \\
\text { echocardiography at the baseline echocardiographic examination }\end{array}$} & 4. Infiltrative/ inflammatory myocardial or pericardial disease \\
\hline & 5. Primary pulmonary arteriopathy \\
\hline \multirow[t]{4}{*}{$\begin{array}{l}\text { 5. Have experienced at least one of the following criteria in the } 12 \\
\text { months before study entry: }\end{array}$} & $\begin{array}{l}\text { 6. Current use of nitrate preparation therapy (will be deleted) or other } \\
\text { PDE5 inhibitors (that is, sildenafil, vardenafil, tadalafil) or cytochrome } \\
\text { P450 3A4 inhibitors (ketoconazole, itraconazole, erythromycin) }\end{array}$ \\
\hline & \\
\hline & $\begin{array}{l}\text { 7. Severe hypotension (SBP }<90 \mathrm{mmHg} \text { or } \mathrm{DBP}<50 \mathrm{mmHg} \text { ) or } \\
\text { uncontrolled hypertension (SBP }>180 \mathrm{mmHg} \text { or } \mathrm{DBP}>100 \mathrm{mmHg} \text { ) }\end{array}$ \\
\hline & $\begin{array}{l}\text { 8. Noncardiac illness with estimated life expectancy }<1 \text { year at the time } \\
\text { of study entry, based on the judgment of the attending physician }\end{array}$ \\
\hline \multirow{4}{*}{$\begin{array}{l}\text { 6. Stable medical therapy for } 1 \text { month before study entry - no } \\
\text { addition or removal or change in major class of medication dosage; } \\
\text { that is, renin-angiotensin-aldosterone inhibitors, } \beta \text {-blockers }\end{array}$} & $\begin{array}{l}\text { 9. Known severe renal dysfunction (GFR }<30 \mathrm{ml} / \text { minute } / 1.73 \mathrm{~m}^{2} \text { by } \\
\text { MDRD equation) }\end{array}$ \\
\hline & $\begin{array}{l}\text { 10. Known severe liver disease (ALT or AST level }>3 \text { times the upper } \\
\text { normal limit, alkaline phosphatase or total bilirubin }>2 \text { times the upper } \\
\text { normal limit) }\end{array}$ \\
\hline & $\begin{array}{l}\text { 11. Actively involved in any physical training program for at least } 6 \\
\text { months before study entry }\end{array}$ \\
\hline & 12. Listed for heart transplantation \\
\hline
\end{tabular}

$A L T$, alanine aminotransferase; $A S T$, aspartate aminotransferase; $D B P$, diastolic blood pressure; FEV1, forced expiratory volume in 1 second; FVC, forced vital capacity; GFR, glomerular filtration rate; MDRD, Modification of Diet in Renal Disease; NYHA, New York Heart Association; SBP, systolic blood pressure.




An independent computer-generated list of random number will be used for participant allocations. Patients will receive either $50 \mathrm{mg}$ udenafil or placebo twice daily for the first 4 weeks, and then if tolerated the dosage will be doubled to $100 \mathrm{mg}$ twice daily for the next 8 weeks. Placebo and active study drugs (that is, udenafil) will appear to be identical and will be provided in blinded kits.

In the phase I trial, 42 healthy male volunteers received 25 to $300 \mathrm{mg}$ of udenafil per day and experienced only minor adverse events [17]. Furthermore, a clinical trial on erectile dysfunction showed that 100 to $200 \mathrm{mg}$ udenafil was well tolerated [18]. Because the half-life of udenafil is 7 to 9 hours, which is longer than that of sildenafil ( 4 hours), the study drug will be provided twice daily. Throughout the trial, medications prescribed by referring physicians will not be changed.

The ULTIMATE-SHF trial has been approved by the Clinical Research Institute at our hospital (H-1102-063352), and the study drug, udenafil, has been approved as Investigational New Drug for therapeutic use in patients with chronic SHF, by the Korean Food and Drug Association.

\section{Blinding}

Study patients, interviewers responsible for administering questionnaires, inspectors that conducted echocardiography and cardiopulmonary exercise tests (CPETs), and the study investigators and directors will be blinded from details of the randomization. Unblinding will be only accepted by the independent data and safety monitoring committee when a serious adverse event occurs, upon request from regulatory authorities, or when information regarding the allocation procedure is deemed important from the perspective of patient safety.

\section{Follow-up protocol}

The trial duration is expected to be 3 months. Participants will attend study visits at screening, baseline, and weeks 4 and 12. At each visit, patients will undergo a complete physical examination, medical history-taking, and an assessment of drug compliance. Investigators will evaluate all clinical and laboratory adverse events at each visit. New York Heart Association functional class and predefined clinical events as described below will be recorded at each clinical visit. Venous blood will be drawn after a 15-minute rest period at screening, and at 4-week and 12-week visits, and will be subjected to the following test battery: B-type natriuretic peptide, complete blood count, electrolyte panel, serum creatinine, and liver function test. At screening visits, echocardiography will be performed at rest, and based on the results obtained study investigators will decide on patient eligibility. At baseline and at 12 weeks, participants will undergo CPET ( $\mathrm{V}_{\operatorname{Max}} 229$ Respiratory Analyzer;
SensorMedics, Homestead, FL, USA) and exercise echocardiography to evaluate exercise capacity in a quantitative manner. At all study visits, researchers will collect health-related information, such as adverse events, admission for acute decompensated $\mathrm{HF}$, and change in medication. In addition, medication compliance of all participants will be carefully assessed by the pill-count method at every visit.

\section{Exercise test protocols}

CPET and combined exercise echocardiography will be performed on a stationary cycle ergometer, since echocardiography should be performed at peak exercise [19]. Exercise echocardiography will be carried out after an overnight fast using a supine bicycle attached to a table tilted 30 to $45^{\circ}$ to the left for best image acquisitions. Subjects will begin exercising at $25 \mathrm{~W}$, and this will be increased by $25 \mathrm{~W}$ after 3 minutes. Workload in metabolic equivalent tasks will be calculated using a previously described standard equation for ergometer exercise [20]. Echocardiographic imaging will be performed continuously during each stage of the exercise protocol using a commercially available ultrasound system (GE vivid 7GE healthcare; Milwaukee WI, USA), and patients will be encouraged to exercise to maximum efforts. Breath-to -breath respiratory gas exchange will be continuously measured with a metabolic cart interfaced to the ergometer. Minute ventilation $\left(V_{E}, 1 /\right.$ minute), carbon dioxide production $\left(\mathrm{V}_{\mathrm{CO} 2}, \mathrm{ml} / \mathrm{kg} /\right.$ minute $)$, oxygen uptake $\left(\mathrm{V}_{\mathrm{O} 2}\right.$, $\mathrm{ml} / \mathrm{kg} / \mathrm{minute}$ ) and respiratory exchange ratio will be calculated. Peak $\mathrm{V}_{\mathrm{O} 2}$ is usually defined as the highest $\mathrm{V}_{\mathrm{O} 2}$ measured during the last minute of symptom-limiting exercise. The ventilatory anaerobic threshold will be determined using the V-slope method [21], and ventilatory efficiency will be determined by calculating the slope of the increase in ventilation with respect to carbon dioxide output $\left(\mathrm{V}_{\mathrm{E}} / \mathrm{V}_{\mathrm{CO} 2}\right)$, with values measured between at rest and the level of anaerobic threshold. To assess hemodynamic changes, echocardiography will be performed at rest and every 3 minutes during exercise by an expert echocardiographer with extensive experience of exercise echocardiography. LV dimensions, LV volumes, LV ejection fractions, mitral $\mathrm{E}$ and $\mathrm{A}$ velocities and corresponding $\mathrm{E} / \mathrm{A}$ ratios, mitral annular $E^{\prime}, A^{\prime}$, and $S^{\prime}$ velocities, $E / E^{\prime}$ ratio, and pulmonary artery systolic pressure (obtained from maximal tricuspid regurgitation velocity determined using continuous wave Doppler) will be carefully obtained.

\section{Safety}

Any participants with a hypersensitivity reaction to the study drug or an adverse event after study medication, those that do not want to remain in the trial, or those that comply with medication $<80 \%$ will be dropped from 
the trial, as will those judged to be at risk due to participation in the trial by an attending physician.

Udenafil has been reported to be safe and well tolerated by healthy volunteers [17], and by patients with erectile dysfunction [14]. No serious adverse events occurred in either study. Common adverse events included nausea, headache, facial flushing, febrile sensation, penile erection, and eyeball pain, all of which have been reported to adverse events of other PDE5 inhibitors. Adverse events will be immediately reported directly to the study investigators, and study staffs will be obligated to manage these events. Patients will be interviewed at each visit about the occurrence of any adverse events, and onset time, duration, and severity will be recorded on case report forms. The possibility of causal relationships between the study drug and the intensities of adverse events will be evaluated by the investigators. The investigators are mandated to report serious adverse events to the institutional review board within 24 hours of recognition. A data and safety monitoring committee will monitor the safety of patients participating in the trial and all ongoing serious adverse events will be closely followed until these conditions have stabilized.

\section{Study withdrawals}

Patients will be permitted to request withdrawal from treatment at any time without providing reasons. The primary investigator and the attending physician will also have authority to drop patients from the trial treatment if it is considered that further participation in the trial would be detrimental to the patient's well-being. Such treatment withdrawals will be documented using a case report form and in patient's medical records. In addition, we have a plan to evaluate the results of this trial in the middle of this study, and based on these interim results the trial can be prematurely terminated if the drug effect would be highly suggested to be beneficial or harmful.

\section{Study endpoints}

The primary outcome will be changes in maximal $\mathrm{V}_{\mathrm{O} 2}$ measured at baseline and at 12-week visits. Maximal $\mathrm{V}_{\mathrm{O} 2}$ will be defined as highest oxygen uptake (averaged over five consecutive breaths) during the last minute of symptom-limited CPET. Secondary endpoints are detailed in Table 2.

\section{Sample size calculation}

Several studies have investigated the therapeutic efficacies of PDE5 inhibitors (the majority employed sildenafil as a study drug) in patients with chronic SHF [10,22]. Most clinical trials have adopted maximal $\mathrm{V}_{\mathrm{O} 2}$ to calculate the sample size and statistical power. In a study of 34 patients with SHF and pulmonary hypertension,
Table 2 Secondary outcomes

Secondary outcomes

1. Changes of ventilator efficiency $\left(\mathrm{V}_{\mathrm{E}} \mathrm{N}_{\mathrm{CO} 2}\right.$ slope $)$

2. Ejection fraction

3. E velocity of mitral inflow, $E^{\prime}$ velocity, systolic mitral annular velocity (S' velocity)

4. E/E' ratio

5. Deceleration time

6. Pulmonary artery systolic pressure measured by echocardiography at baseline and 12 weeks

7. Post-exercise pulmonary artery systolic pressure measured by echocardiography at baseline and 12 weeks

8. Symptomatic status (NYHA functional class and Borg dyspnea index)

9. Plasma concentration of BNP assessed at baseline, 4 weeks, and 12 weeks

10. Clinical endpoints, all-cause death, cardiac death, admission for heart failure, and the composites of these events will be assessed until the end of the study period

11. Development of facial flushing, febrile sensation, eyeball pain, visual disturbance, headache, penile erection, intolerance or development of other adverse drug reactions related with study drug will be assessed

$B N P$, B-type natriuretic peptide; NYHA, New York Heart Association; $V_{E}$, minute ventilation (l/minute); $\mathrm{V}_{\mathrm{CO} 2}$, carbon dioxide production ( $\mathrm{ml} / \mathrm{kg} / \mathrm{minute}$ ).

Lewis and colleagues reported a $14 \%$ increase in maximal $\mathrm{V}_{\mathrm{O} 2}$ by sildenafil administration (from $12.2 \pm 0.7$ to $13.9 \pm 1.0 \mathrm{ml} / \mathrm{g} /$ minute) $[10]$. On the other hand, in a study investigating the efficacy of sildenafil in 23 patients with SHF, Guazzi and colleagues reported an increase in maximal $\mathrm{V}_{\mathrm{O} 2}$ of approximately $21 \%$ (from $12.9 \pm 6.8$ to $15.6 \pm 6.0 \mathrm{ml} / \mathrm{minute} / \mathrm{kg}$ ) [22]

Assuming a mean baseline maximal $\mathrm{V}_{\mathrm{O} 2}$ of $14.0 \mathrm{ml} /$ $\mathrm{kg} /$ minute, a percentage increase in maximal $\mathrm{V}_{\mathrm{O} 2}$ of $0 \%$ in the placebo group and $15 \%$ in the udenafil group (data taken from the study by Lewis and colleagues [10] and our previous experiences), we anticipate final maximal $\mathrm{V}_{\mathrm{O} 2}$ values of $14.0 \mathrm{ml} / \mathrm{kg} /$ minute in the placebo group and of $16.1 \mathrm{ml} / \mathrm{kg} /$ minute in the udenafil group, with a conservative standard deviation for mean maximal $\mathrm{V}_{\mathrm{O} 2}$ of $2.5 \mathrm{ml} / \mathrm{kg} /$ minute. Accordingly, we calculated the sample size assuming a standard deviation of $2.5 \mathrm{ml} / \mathrm{kg} / \mathrm{minute}$ using the following formula:

$$
n_{i}=\frac{2\left(Z_{a / 2}+Z_{\beta}\right)^{2} \sigma^{2}}{\left(\mu_{1}-\mu_{2}\right)^{2}}
$$

Based on these assumptions and calculations, detection of the $15 \%$ increase in maximal $\mathrm{V}_{\mathrm{O} 2}$ by udenafil, with a power of $80 \%$ and a statistical significance level of $5 \%$, will require 23 patients per group for a standard deviation of $2.5 \mathrm{ml} / \mathrm{kg} /$ minute. Thus, allowing for a loss of $10 \%$ (data are missing completely at random, which implies that the missing data are unrelated to the study 
variables), a maximum of 52 patients would be required or 26 patients per group.

\section{Statistical considerations}

The principal analysis will be conducted on an intentionto-treat basis. We will analyze all patients according to the randomization scheme. However, data that are missing completely at random will be omitted without analysis. The differences between the treatment groups in the main outcome will be assessed using an unpaired $t$ test adjusted by baseline values (analysis of covariance). Binary endpoints will be compared using Fisher's exact probability test. For survival analysis and clinical events, KaplanMeier survival curves will be plotted and compared using the log-rank test based on a proportional hazards model using the chi-square test. Statistical significance will be accepted for $P<0.05$.

\section{Discussion}

Vasoconstriction is a pathophysiological hallmark of chronic HF, which involves the systemic and pulmonary circulations, and results in increased impedance of the left and the right ventricular ejection. Defective nitric oxide release is a major contributor to vasoconstriction in chronic HF [6]. The potentiation of nitric oxide signaling thus represents an interesting pharmacological approach. Furthermore, the inhibition of PDE5, the predominant isoenzyme that metabolizes cGMP [23], has attracted interest as a potential therapeutic tool in chronic SHF. Experiences accumulated in patients with pulmonary arterial hypertension provided the rationale for a therapeutic PDE5 inhibition in chronic SHF. Since the first description of the favorable effects of PDE5 inhibitors in pulmonary arterial hypertension [7], the positive effects of PDE5 inhibition on cardiac remodeling and secondary pulmonary hypertension have raised the possibility that chronic PDE5 inhibition offers a potential adjunct to the current pharmacological management of chronic SHF [10,22,24]. In addition, cGMP upregulation by PDE 5 inhibition has also been reported to modulate the contractility of hypertrophied right ventricles [25].

Sildenafil was the first PDE5 inhibitor introduced to the clinical arena, and thus has been extensively investigated in experimental and clinical cardiology research sectors. Bocchi and colleagues evaluated the efficacy of sildenafil for the treatment of erectile dysfunction in patients with chronic SHF, and found that sildenafil improved exercise capacity [26]. Furthermore, in a study of 13 chronic SHF patients of New York Heart Association class III, Lewis and colleagues showed that sildenafil improves maximal $\mathrm{V}_{\mathrm{O} 2}$ and reduces $\mathrm{V}_{\mathrm{E}} / \mathrm{V}_{\mathrm{CO} 2}$ slope [10]. As a result of these studies, PDE5 inhibitors are now considered good candidates for the treatment of chronic SHF.
Some PDE5 inhibitor brands can now be prescribed. However, although these PDE5 inhibitors are similar in terms of mode of action and molecular structures, their potencies, pulmonary vessel selectivities, and half-lives differ [27]. As a representative example, the onset of action of sildenafil is rapid, and as mentioned above its plasma half-life is 4 hours $[28,29]$, which means that patients take the medication three times a day. In contrast, the plasma half-life of udenafil is 7 to 9 hours, and thus medications can be reduced to twice daily so patient compliance should improve [30] and eventually prognosis should benefit [31]. In this trial, the relatively shortterm effects of udenafil on the exercise capacity of chronic SHF patients will be evaluated. Notwithstanding, we believe that this study will open a door to new therapeutic prospects for the long-acting PDE5 inhibitor, udenafil, and will help provide a new therapeutic option for chronic SHF patients.

The proposed ULTIMATE-SHF trial, as outlined above, will be a randomized, placebo-controlled, doubleblind clinical trial designed to investigate the therapeutic effect of a new, long-acting PDE5 inhibitor, udenafil, in patients with chronic SHF. If an improvement in exercise capacity, as determined by peak $\mathrm{V}_{\mathrm{O} 2}$, is demonstrated, udenafil could become a valuable therapeutic auxiliary for patients with chronic SHF that receive maximal medical management for SHF based on the current guidelines [16].

\section{Trial status}

Patient recruitment.

\section{Abbreviations \\ CGMP: Cyclic guanine monophosphate; CPET: Cardiopulmonary exercise test; HF: Heart failure; LV: Left ventricular; PDE5: Phosphodiesterase type 5; SHF: Systolic heart failure; $V_{E}$ : Minute ventilation ( $1 /$ minute); $V_{\mathrm{CO}_{2}}$ : Carbon dioxide production ( $\mathrm{ml} / \mathrm{kg} /$ minute); $V_{\mathrm{O} 2}$ : Oxygen uptake ( $\mathrm{ml} / \mathrm{kg} / \mathrm{minute}$ ).}

\section{Competing interests}

The authors declare that they have no competing interests.

\section{Authors' contributions}

$\mathrm{KHK}, \mathrm{HKK}$ and $\mathrm{ICH}$ contributed to the study design and performed the analysis. HJC,HJK, HKK, SPL, YJK, and DWS recruited patients and interpreted data. KHK and HKK wrote the manuscript. All authors read and approved the final manuscript.

\section{Acknowledgements}

The ULTIMATE-SHF trial is funded by the Korea Healthcare Technology Research and Development Project, Ministry for Health, Welfare, and Family Affairs, Republic of Korea (A102169)

Received: 24 March 2013 Accepted: 6 June 2013

Published: 22 June 2013

\section{References}

1. Eriksson H: Heart failure: a growing public health problem. $J$ Internal Med 2009, 237:135-141.

2. Petrie M, Murray JM: Changes in notions about heart failure. Lancet 2001, 358:432-434. 
3. Ghio S, Gavazzi A, Campana C, Inserra C, Klersy C, Sebastiani R, Arbustini E, Recusani F, Tavazzi L: Independent and additive prognostic value of right ventricular systolic function and pulmonary artery pressure in patients with chronic heart failure. J Am Coll Cardiol 2001, 37:183-188.

4. Costard-Jäckle A, Fowler MB: Influence of preoperative pulmonary artery pressure on mortality after heart transplantation: testing of potential reversibility of pulmonary hypertension with nitroprusside is useful in defining a high risk group. J Am Coll Cardiol 1992, 19:48-54.

5. Cohen AH, Hanson K, Morris K, Fouty B, McMurty IF, Clarke W, Rodman DM: Inhibition of cyclic 3'5'-guanosine monophosphate-specific phosphodiesterase selectively vasodilates the pulmonary circulation in chronically hypoxic rats. J Clin Invest 1996, 97:172-179.

6. Saraiva RM, Hare JM: Nitric oxide signaling in the cardiovascular system: implications for heart failure. Curr Opin Cardiol 2006, 21:221-228.

7. Prasad S, Wilkinson J, Gatzoulis MA: Sildenafil in primary pulmonary hypertension. N Engl J Med 2000, 343:1342.

8. Guazzi M, Tumminello G, Di Marco F, Fiorentini C, Guazzi MD: The effects of phosphodiesterase- 5 inhibition with sildenafil on pulmonary hemodynamics and diffusion capacity, exercise ventilatory efficiency, and oxygen uptake kinetics in chronic heart failure. J Am Coll Cardiol 2004, 44:2339-2348.

9. Sastry BK, Narasimhan C, Reddy NK, Raju BS: Clinical efficacy of sildenafil in primary pulmonary hypertension: a randomized, placebo-controlled, double-blind, crossover study. J Am Coll Cardio/ 2004, 43:1149-1153.

10. Lewis GD, Shah R, Shahzad K, Camuso JM, Pappagianopoulos PP, Hung J, Tawakol A, Gerszten RE, Systrom DM, Bloch KD, Semigran MJ: Sildenafil improves exercise capacity and quality of life in patients with systolic heart failure and secondary pulmonary hypertension. Circulation 2007 116:1555-1562.

11. Salem EA, Kendirci M, Hellstrom WJ: Udenafil, a long-acting PDE5 inhibitor for erectile dysfunction. Curr Opin Investig Drugs 2006, 7:661-669.

12. Kim TE, Kim BH, Kim JR, Lim KS, Hong JH, Kim KP, Kim HS, Shin SG, Jang IJ, Yu KS: Effect of food on the pharmacokinetics of the oral phosphodiesterase 5 inhibitor udenafil for the treatment of erectile dysfunction. Br J Clin Pharmacol 2009, 68(1):43-6.

13. Kouvelas D, Goulas A, Papazisis G, Sardeli C, Pourzitaki C: PDE5 inhibitors: in vitro and in vivo pharmacological profile. Curr Pharm Des 2009, 15:3464-3475.

14. Paick JS, Kim SW, Yang DY, Kim JJ, Lee SW, Ahn TY, Choi HK, Suh JK, Kim SC: The efficacy and safety of udenafil, a new selective phosphodiesterase type 5 inhibitor, in patients with erectile dysfunction. J Sex Med 2008, 5:946-953.

15. Kang KK, Ahn GJ, Sohn YS, Ahn BO, Kim WB: DA-8159, a new PDE5 inhibitor, attenuates the development of compensatory right ventricular hypertrophy in a rat model of pulmonary hypertension. J Int Med Res 2003, 31:517-528.

16. Hunt SA, Abraham WT, Chin MH, Feldman AM, Francis GS, Ganiats TG, Jessup M, Konstam MA, Mancini DM, Michl K, Oates JA, Rahko PS, Silver MA, Stevenson LW, Yancy CW: 2009 focused update incorporated into the ACC/AHA 2005 Guidelines for the Diagnosis and Management of Heart Failure in Adults: a report of the American College of Cardiology Foundation/American Heart Association Task Force on Practice Guidelines: developed in collaboration with the International Society for Heart and Lung Transplantation. Circulation 2009, 119:e391-e479.

17. Kim BH, Lim HS, Chung JY, Kim JR, Lim KS, Sohn DR, Cho JY, Yu KS, Shin SG, Paick JS, Jang IJ: Safety, tolerability and pharmacokinetics of udenafil, a novel PDE-5 inhibitor, in healthy young Korean subjects. $\mathrm{Br} J \mathrm{Clin}$ Pharmacol 2008, 65:848-854.

18. Park HJ, Park JK, Park K, Min K, Park NC: Efficacy of udenafil for the treatment of erectile dysfunction up to 12 hours after dosing: a randomized placebo-controlled trial. J Sex Med 2010, 7:2209-2216.

19. Balady GJ, Arena R, Sietsema K, Myers J, Coke L, Fletcher GF, Forman D, Franklin B, Guazzi M, Gulati M, Keteyian SJ, Lavie CJ, Macko R, Mancini D, Milani RV: Clinician's Guide to cardiopulmonary exercise testing in adults: a scientific statement from the American Heart Association. Circulation 2010, 122:191-225.

20. Froelicher VF, Myers JN: Interpretation of hemodynamic responses to exercise testing. In Exercise and the Heart. 4th edition. Edited by Froelicher VF, Myers JN. Philadelphia, PA: WB Saunders; 2000:93-120.

21. Beaver WL, Wasserman $K$, Whipp BJ: A new method for detecting anaerobic threshold by gas exchange. J Appl Physiol 1986, 60:2020-2027.
22. Guazzi M, Vicenzi M, Arena R, Guazzi MD: PDE5 inhibition with sildenafil improves left ventricular diastolic function, cardiac geometry, and clinical status in patients with stable systolic heart failure: results of a 1-year, prospective, randomized, placebo-controlled study. Circ Heart Fail 2011, 4:8-17.

23. Palmer RM, Ashton DS, Moncada S: Vascular endothelial cells synthesize nitric oxide from L-arginine. Nature 1988, 333:664-666

24. Guazzi M, Samaja M: The role of PDE5-inhibitors in cardiopulmonary disorders: from basic evidence to clinical development. Curr Med Chem 2007, 14:2181-2191.

25. Nagendran J, Archer SL, Soliman D, Gurtu V, Moudgil R, Haromy A St Aubin C, Webster L, Rebeyka IM, Ross DB, Light PE, Dyck JR, Michelakis ED: Phosphodiesterase type 5 is highly expressed in the hypertrophied human right ventricle, and acute inhibition of phosphodiesterase type 5 improves contractility. Circulation 2007, 116:238-248.

26. Bocchi EA, Guimaraes G, Mocelin A, Bacal F, Bellotti G, Ramires JF: Sildenafil effects on exercise, neurohormonal activation, and erectile dysfunction in congestive heart failure: a double-blind, placebo-controlled, randomized study followed by a prospective treatment for erectile dysfunction. Circulation 2002, 106:1097-1103.

27. Teixeira CE, Priviero FB, Webb RC: Differential effects of the phosphodiesterase type 5 inhibitors sildenafil, vardenafil, and tadalafil in rat aorta. J Pharmacol Exp Ther 2006, 316:654-661.

28. Padma-Nathan $H$, Stecher VJ, Sweeney M, Orazem J, Tseng $L$, Deriesthal $H$ : Minimal time to successful intercourse after sildenafil citrate: results of a randomized, double-blind, placebo-controlled trial. Urology 2003, 62:400-403

29. Walker DK, Ackland MJ, James GC, Muirhead GJ, Rance DJ, Wastall P, Wright PA: Pharmacokinetics and metabolism of sildenafil in mouse, rat, rabbit, dog and man. Xenobiotica 1999, 29:297-310.

30. Frishman WH: Importance of medication adherence in cardiovascular disease and the value of once-daily treatment regimens. Cardiol Rev 2007, 15:257-263.

31. Fitzgerald AA, Powers JD, Ho PM, Maddox TM, Peterson PN, Allen LA, Masoudi FA, Magid DJ, Havranek EP: Impact of medication nonadherence on hospitalizations and mortality in heart failure. J Card Fail 2011, 17:664-669

doi:10.1186/1745-6215-14-188

Cite this article as: Kim et al:: ULTIMATE-SHF trial (UdenafiL Therapy to Improve symptoMAtology, exercise Tolerance and hEmodynamics in patients with chronic systolic heart failure): study protocol for a randomized, placebo-controlled, double-blind trial. Trials 2013 14:188.

\section{Submit your next manuscript to BioMed Central and take full advantage of:}

- Convenient online submission

- Thorough peer review

- No space constraints or color figure charges

- Immediate publication on acceptance

- Inclusion in PubMed, CAS, Scopus and Google Scholar

- Research which is freely available for redistribution

Submit your manuscript at www.biomedcentral.com/submit
C Biomed Central 